\title{
Neutralizing activities against seasonal influenza viruses in human intravenous immunoglobulin
}

This article was published in the following Dove Press journal:

Biologics:Targets and Therapy

10 March 2017

Number of times this article has been viewed

\author{
Hiroyuki Onodera' \\ Takeru Urayama ${ }^{2}$ \\ Kazue Hirota ${ }^{3}$ \\ Kazuhiro Maeda ${ }^{3}$ \\ Ritsuko Kubota-Koketsu ${ }^{3,4}$ \\ Kazuo Takahashi ${ }^{5}$ \\ Katsuro Hagiwara ${ }^{6}$ \\ Yoshinobu Okuno ${ }^{3}$ \\ Kazuyoshi lkuta ${ }^{3,4}$ \\ Mikihiro Yunoki ${ }^{2,4,6}$ \\ 'Medical Information Department, \\ ${ }^{2}$ Research and Development Division, \\ Japan Blood Products Organization, \\ Tokyo, ${ }^{3}$ Research and Development \\ Division, The Research Foundation \\ for Microbial Diseases of Osaka \\ University, Kagawa, ${ }^{4}$ Former \\ Department of Virology, Research \\ Institute for Microbial Diseases, \\ Osaka University, ${ }^{5}$ Virology Division, \\ Department of Infectious Diseases, \\ Osaka Prefectural Institute of \\ Public Health, Osaka, ${ }^{6}$ Pathogenic \\ Risk Evaluation, Graduate School of \\ Veterinary Medicine, Rakuno Gakuen \\ University, Hokkaido, Japan
}

Mikihiro Yunoki

Research and Development Division, Japan Blood Products Organization, $7 \mathrm{~F}$ World Trade Center Building, 2-4-I, Hamamatsu-cho, Minato-ku, Tokyo 105-6107, Japan

Email Yunoki-mikihiro@jbpo.or.jp

Ritsuko Kubota-Koketsu

Research and Development Division, The Research Foundation for Microbial Diseases of Osaka University, 3-I, Yamadaoka, Suita, Osaka 565-087I, Japan

Email rkoketsu@mail.biken.or.jp

\begin{abstract}
Influenza viruses A/H1N1, A/H3N2, and B are known seasonal viruses that undergo annual mutation. Intravenous immunoglobulin (IVIG) contains anti-seasonal influenza virus globulins. Although the virus-neutralizing (VN) titer is an indicator of protective antibodies, changes in this titer over extended time periods have yet to be examined. In this study, variations in hemagglutination inhibition (HI) and VN titers against seasonal influenza viruses in IVIG lots over extended time periods were examined. In addition, the importance of monitoring the reactivity of IVIG against seasonal influenza viruses with varying antigenicity was evaluated. A/H1N1, A/H3N2, and B influenza virus strains and IVIG lots manufactured from 1999 to 2014 were examined. The HI titer was measured by standard methods. The VN titer was measured using a micro-focus method. IVIG exhibited significant $\mathrm{HI}$ and VN titers against all investigated strains. Our results suggest that the donor population maintains both specific and cross-reactive antibodies against seasonal influenza viruses, except in cases of pandemic viruses, despite major antigen changes. The titers against seasonal influenza vaccine strains, including past strains, were stable over short time periods but increased slowly over time.
\end{abstract}

Keywords: IVIG, influenza, seasonal, neutralization, vaccine

\section{Introduction}

Influenza viruses $\mathrm{A} / \mathrm{H} 1 \mathrm{~N} 1, \mathrm{~A} / \mathrm{H} 3 \mathrm{~N} 2$, and $\mathrm{B}$ are known seasonal viruses that undergo annual mutation. Therefore, to control/prevent influenza, vaccine programs against virus strains are determined every season by the World Health Organization and implemented by the health authorities of various countries. Intravenous immunoglobulin (IVIG) possesses significant neutralizing activities against influenza viruses. ${ }^{1-4}$ IVIG is manufactured from pooled plasma that is derived from $>10,000$ healthy donors. Therefore, IVIG contains various antibodies against numerous human pathogens. The anti-seasonal influenza virus activity of IVIG seems to be an accumulation of host reactions against previous vaccinations and natural infections. Consequently, IVIG maintains a high neutralizing titer reflecting the epidemiological status of the donor population at a given time period and region.

The virus-neutralizing (VN) titer is considered a significant indicator of IVIG activity. However, anti-influenza virus activity is usually determined by the hemagglutination inhibition (HI) titer. This assay evaluates the inhibition of viral particles bound to sialic acid. In contrast, the VN assay evaluates the inhibition of viral attachment and penetration into the cell and the release of progeny virus particles. Although $\mathrm{VN}$ is considered a more significant functional marker than $\mathrm{HI}$, the fluctuation of VN 
activity in IVIG lots over extended time periods has yet to be carefully evaluated. Here, we determined the fluctuation in HI and VN titers in IVIG lots manufactured from 2009 to 2014 by examining their activities against influenza A/H1N1, $\mathrm{A} / \mathrm{H} 3 \mathrm{~N} 2$, and $\mathrm{B}$ vaccine strains. In addition, we evaluated the fluctuation in HI and VN titers in several IVIG lots following prolonged storage (1999 to 2009) to evaluate how they responded to virus antigenic mutations in adults over the long term.

\section{Materials and methods}

The influenza A/H1N1 viruses were A/Yamagata/32/1989 (A/Yam), A/New Caledonia/20/1999 (A/NC), A/Brisbane/59/2007 (A/Bri), and A/California/7/2009 (A/Cal). Two clinical isolates, A/Osaka/18/2008 and A/Osaka/16/2008, were also used. The influenza A/H3N2 viruses were A/Uruguay/716/2007 (A/Uru), A/Victoria/210/2009 (A/Vic210), A/Victoria/361/2009 (A/Vic361), A/Texas/50/2012 (A/Tex), and $\mathrm{A} / \mathrm{New}$ York/39/2012 (A/NY). The influenza B viruses were B/Florida/4/2006 (B/Flo), B/Brisbane/60/2008 (B/Bri), B/Wisconsin/01/2010 (B/Wis), and B/Massachusetts/02/2012 (B/Mas). The seasonal influenza vaccine strains from 2006 to 2015 are summarized in Table 1 .

Three IVIGs, Venoglobulin IH 5\% I.V. (V-IH; Japan Blood Products Organization, Tokyo, Japan; formerly the Benesis Corporation, Osaka, Japan [manufactured from 1999 to 2014]), Nisseki Polyglobin-N 5\% I.V. (Poly-N; formerly the Japanese Red Cross Society, Tokyo, Japan [manufactured from 2013 to 2014]), and Poly-N 10\% I.V. (formerly the Japanese Red Cross Society [manufactured from 2013 to 2014]), were used in this study. Experiments using these IVIGs were approved by the ethical committee of the Japan Blood Products Organization.

The VN assays were performed at two facilities (Facilities A and B) using identical protocols. In brief, viruses were propagated in Madin-Darby canine kidney (MDCK) cells and the allantoic cavity of 10-day-old embryonated chicken eggs. Culture media and allantoic fluid were aliquoted and stored at $-80^{\circ} \mathrm{C}$ prior to use. Virus infectivity was titrated by focus-forming units/mL in MDCK cells using the peroxidase-anti-peroxidase staining technique (micro-focus method). ${ }^{2,4,5}$ The results are expressed as the reciprocal of the lowest dilution demonstrating $>50 \%$ neutralization. The HI assays were performed at a commercial test company (Facility C). The results are expressed as the reciprocal of the highest two-fold serial IVIG dilution demonstrating HI.

\section{Results}

The HI and VN titers of IVIG lots against the A/H1N1 influenza vaccine strains used from seasons 2008/09 to 2014/15 (A/Bri [to 2009/10] and A/Cal [from 2009/10]) are shown in Figure 1. The titers were stable for $\mathrm{A} / \mathrm{Bri}$ but decreased with time when the virus was changed to $\mathrm{A} / \mathrm{Cal}$. Interestingly, the titers against $\mathrm{A} / \mathrm{Cal}$ in lots manufactured from late 2010 to 2012, derived from source plasma collected before 2009 , showed weak reactivity. This result suggested that the donor population had crossreactive globulin against pandemic $\mathrm{A} / \mathrm{Cal}$. The titers increased in lots manufactured from 2012 to 2013 , derived from source plasma collected around 2009. These results seem to indicate a major antigen change, such as an antigenic shift in the 2009 pandemic, and that the donor population quickly developed the anti-A/Cal-specific globulin by viral infection and/or vaccination. The HI and VN titers were correlated.

The $\mathrm{HI}$ and $\mathrm{VN}$ titers against the $\mathrm{A} / \mathrm{H} 3 \mathrm{~N} 2$ influenza vaccine strains from seasons $2008 / 09$ to $2014 / 15$ (A/Uru [2008/09-2009/10], A/Vic210 [2010/11-2011/12], A/Vic361 [2012/13], A/Tex [2013/14], and A/NY [2014/15]) are shown in Figure 2. These results indicate that the antibody titers were stable over short time periods but slowly increased over extended periods. This suggests that the A/H3N2 virus did

Table I Vaccine strains from 2005/06 to 20I4/I5 seasons in Japan

\begin{tabular}{lllll}
\hline Seasons & A HIN I & & A H3N2 & B (lineage) \\
\cline { 2 - 3 } & Before 2009 pandemic & After 2009 pandemic & & \\
\hline $2005 / 06$ & A/New Caledonia/20/1999 & - & A/New York/55/2004 & B/Shanghai/36I/2002 (Yamagata) \\
$2006 / 07$ & A/New Caledonia/20/1999 & - & A/Hiroshima/52/2005 & B/Malaysia/2506/2004 (Victoria) \\
$2007 / 08$ & A/Solomon Islands/3/2006 & - & A/Hiroshima/52/2005 & B/Malaysia/2506/2004 (Victoria) \\
$2008 / 09$ & A/Brisbane/59/2007 & - & A/Uruguay/7/6/2007 & B/Florida/4/2006 (Yamagata) \\
$2009 / 10$ & A/Brisbane/59/2007 & - & A/Uruguay/7/6/2007 & B/Brisbane/60/2008 (Victoria) \\
$2009 / 10$ & - & A/California/7/2009 & - & - \\
$2010 / 11$ & - & A/California/7/2009 & A/Victoria/210/2009 & B/Brisbane/60/2008 (Victoria) \\
$2011 / 12$ & - & A/California/7/2009 & A/Victoria/210/2009 & B/Brisbane/60/2008 (Victoria) \\
$2012 / 13$ & - & A/California/7/2009 & A/Victoria/36I/20II & B/Wisconsin/0I/2010 (Yamagata) \\
$2013 / 14$ & - & A/California/7/2009 & A/Texas/50/2012 & B/Massachusetts/02/20I2 (Yamagata) \\
$2014 / 15$ & - & A/California/7/2009 & A/New York/39/2012 & B/Massachusetts/02/2012 (Yamagata) \\
\hline
\end{tabular}




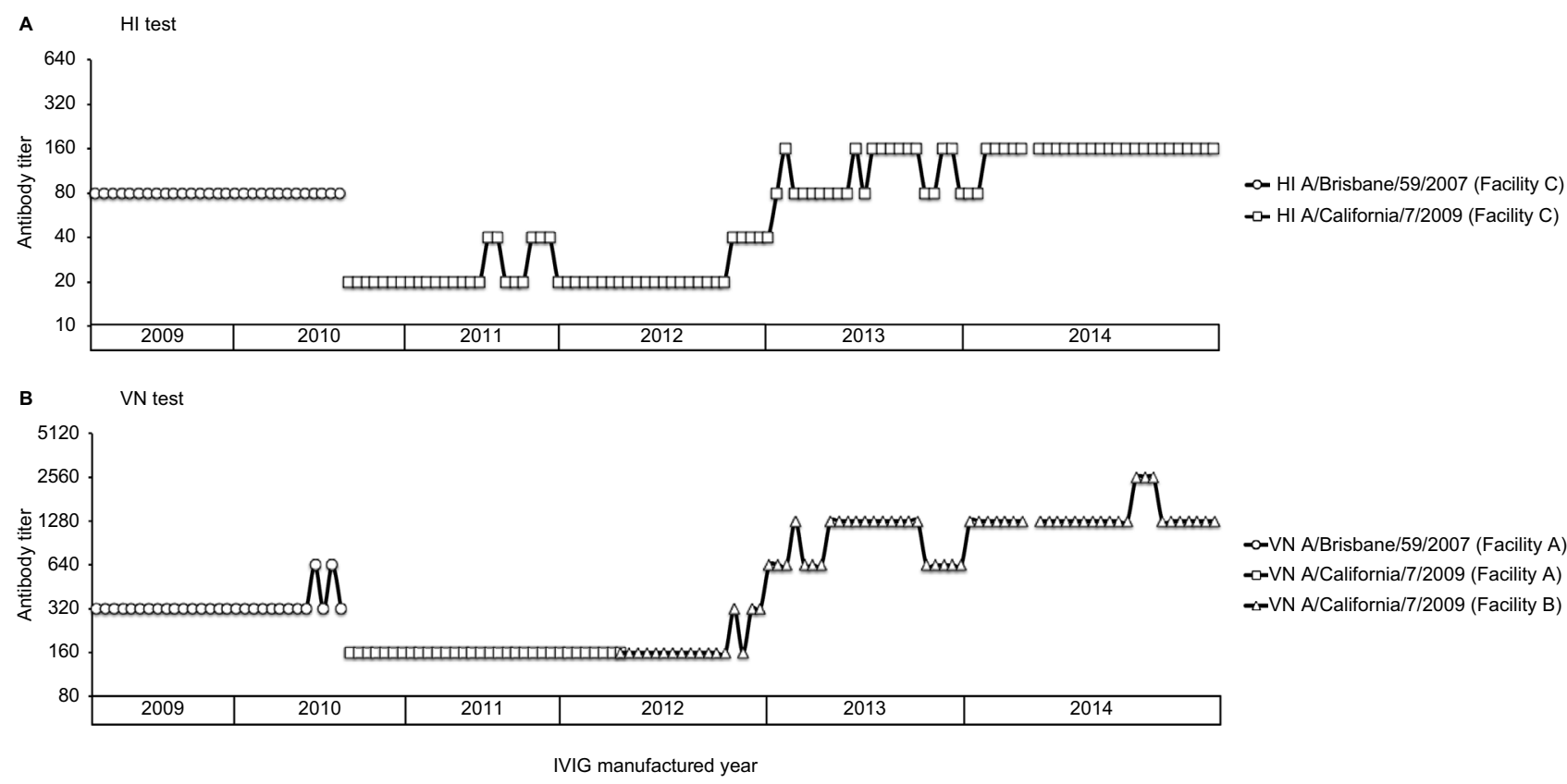

Figure I Changes in antibody titers against A/HINI influenza viruses in $\mathrm{V}-\mathrm{IH}$ lots manufactured from 2009 to 2014.

Notes: (A) HI titers. Open circle: A/Brisbane/59/2007 (until 2010); open square: A/California/7/2009 (from 2010). Both tests were performed in Facility C. (B) VN titers. Open circle: A/Brisbane/59/2007 in Facility A until 2010; open square: A/California/7/2009 in Facility A between 2010 and 2012; open triangle: A/California/7/2009 in Facility B from 2012.

Abbreviations: V-IH, Venoglobulin IH; HI, hemagglutination inhibition; VN, virus neutralizing; IVIG, intravenous immunoglobulin.

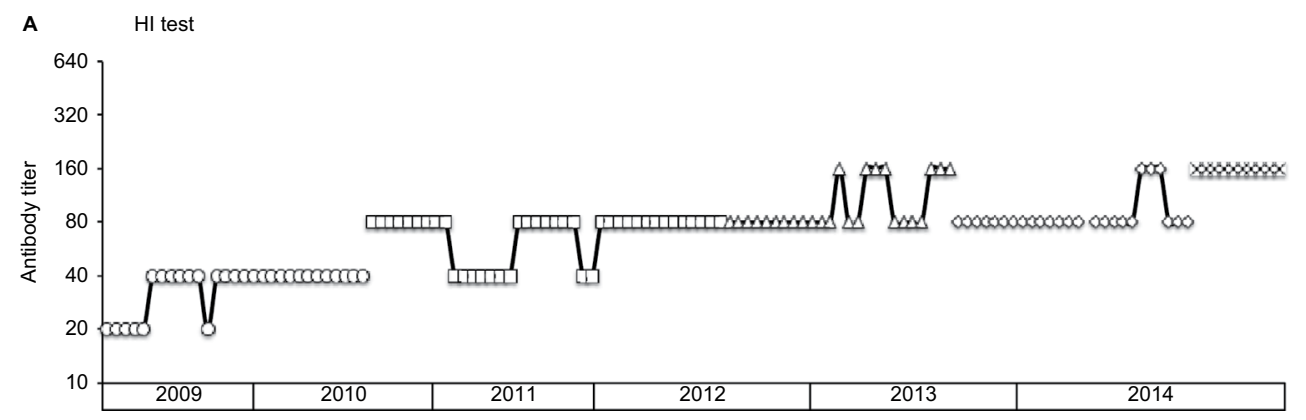

- HI A/Uruguay/716/2007 (Facility C) $\rightarrow-$ HI A/Victoria/210/2009 (Facility C) $\neg-\mathrm{HI}$ A/Victoria/361/2011 (Facility C) $\curvearrowright$ HI A/Texas/50/2012 (Facility C) -x- HI A/New York/39/2012 (Facility C)

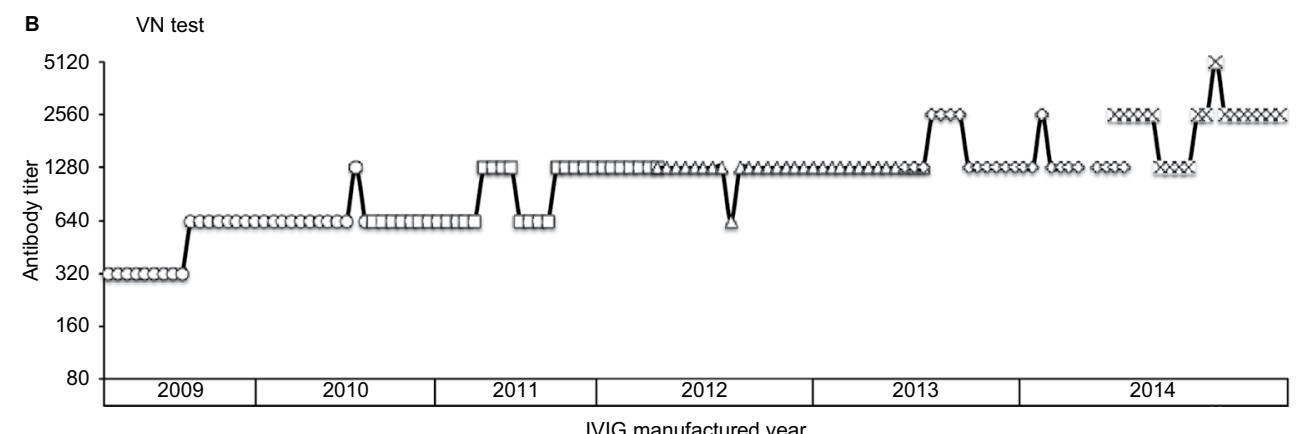

Figure 2 Changes in antibody titers against $\mathrm{A} / \mathrm{H} 3 \mathrm{~N} 2$ influenza viruses in $\mathrm{V}-\mathrm{IH}$ lots manufactured from 2009 to 2014.

Notes: (A) HI titers. Open circle: A/Uruguay/7/6/2007 until 20I0; open square: A/Victoria/210/2009 between 20I0 and 20I2; open triangle: A/Victoria/36I/20II between 2012 and 2013; open diamond: A/Texas/50/20I2 between 2013 and 20I4; cross: A/New York/39/20I2 from 2014. All tests were performed in Facility C. (B) Virusneutralizing (VN) titers. Open circle: A/Uruguay/7/6/2007 in Facility A until 20I0; open square: A/Victoria/210/2009 in Facility A between 20I0 and 20I2; open triangle: A/Victoria/36I/20II in Facility B between 2012 and 20I3; open diamond: A/Texas/50/20I2 in Facility B between 20I3 and 20I4; cross: A/New York/39/20I2 in Facility B from 2014.

Abbreviations: V-IH, Venoglobulin $\mathrm{IH} ; \mathrm{HI}$, hemagglutination inhibition; VN, virus neutralizing; IVIG, intravenous immunoglobulin. 


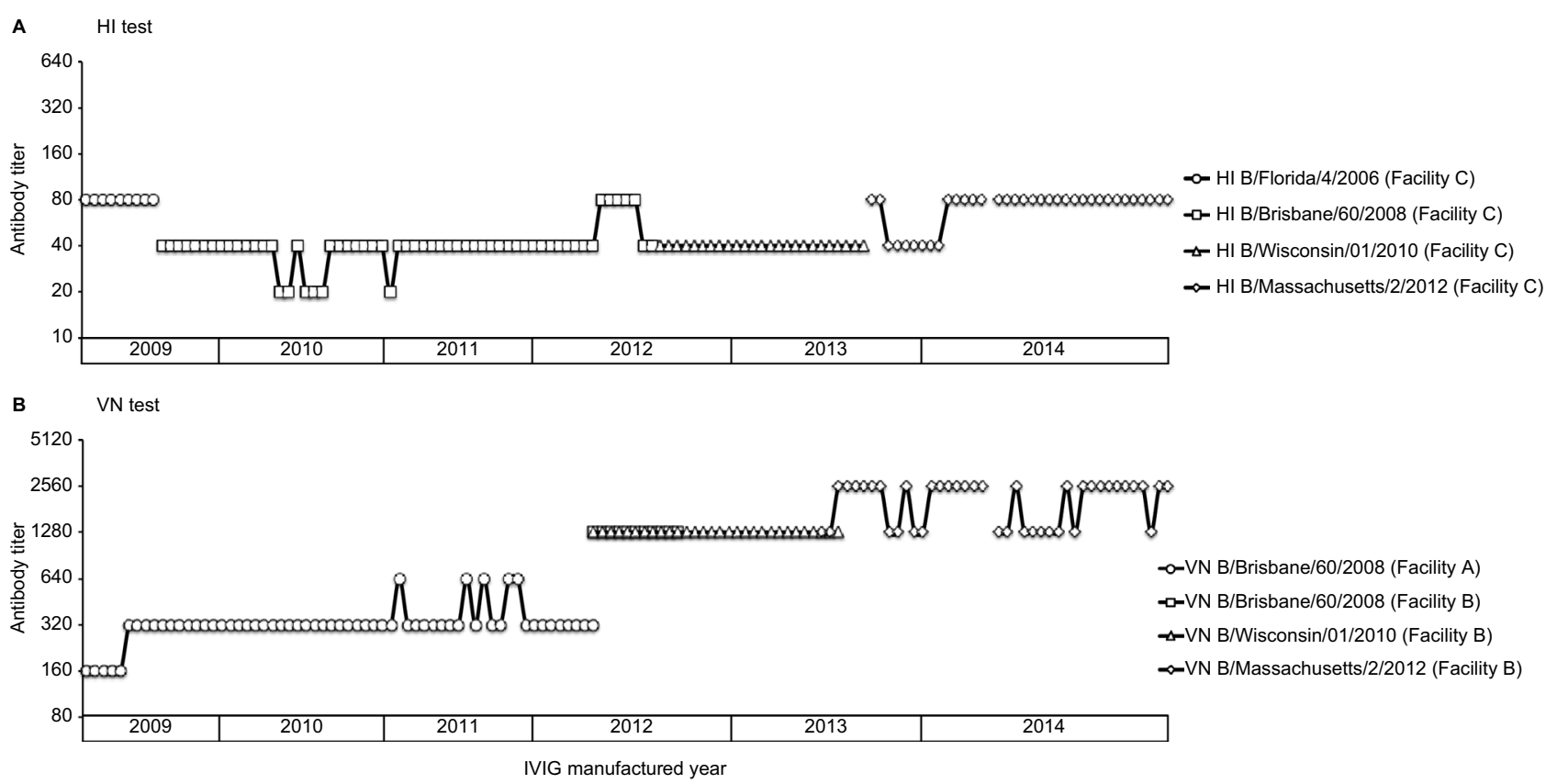

Figure 3 Changes in antibody titers against B influenza viruses in V-lH lots manufactured from 2009 to 2014.

Notes: (A) HI titers. Open circle: B/Florida/4/2006 until 2009; open square: B/Brisbane/60/2008 between 2009 and 2012; open triangle: B/Wisconsin/0I/20I0 between 20I2 and 2013; open diamond: B/Massachusetts/2/20I2 from 20I3. All tests were performed in Facility C. (B) VN titers. Open circle: B/Brisbane/60/2008 in Facility A until 20I2; open square: $B / B r i s b a n e / 60 / 2008$ in Facility $B$ in 20I2; open triangle: B/Wisconsin/0I/2010 in Facility B between 2012 and 20I3; open diamond: B/Massachusetts/2/20I2 in Facility B from 2013.

Abbreviations: V-IH, Venoglobulin IH; HI, hemagglutination inhibition; VN, virus neutralizing; IVIG, intravenous immunoglobulin.
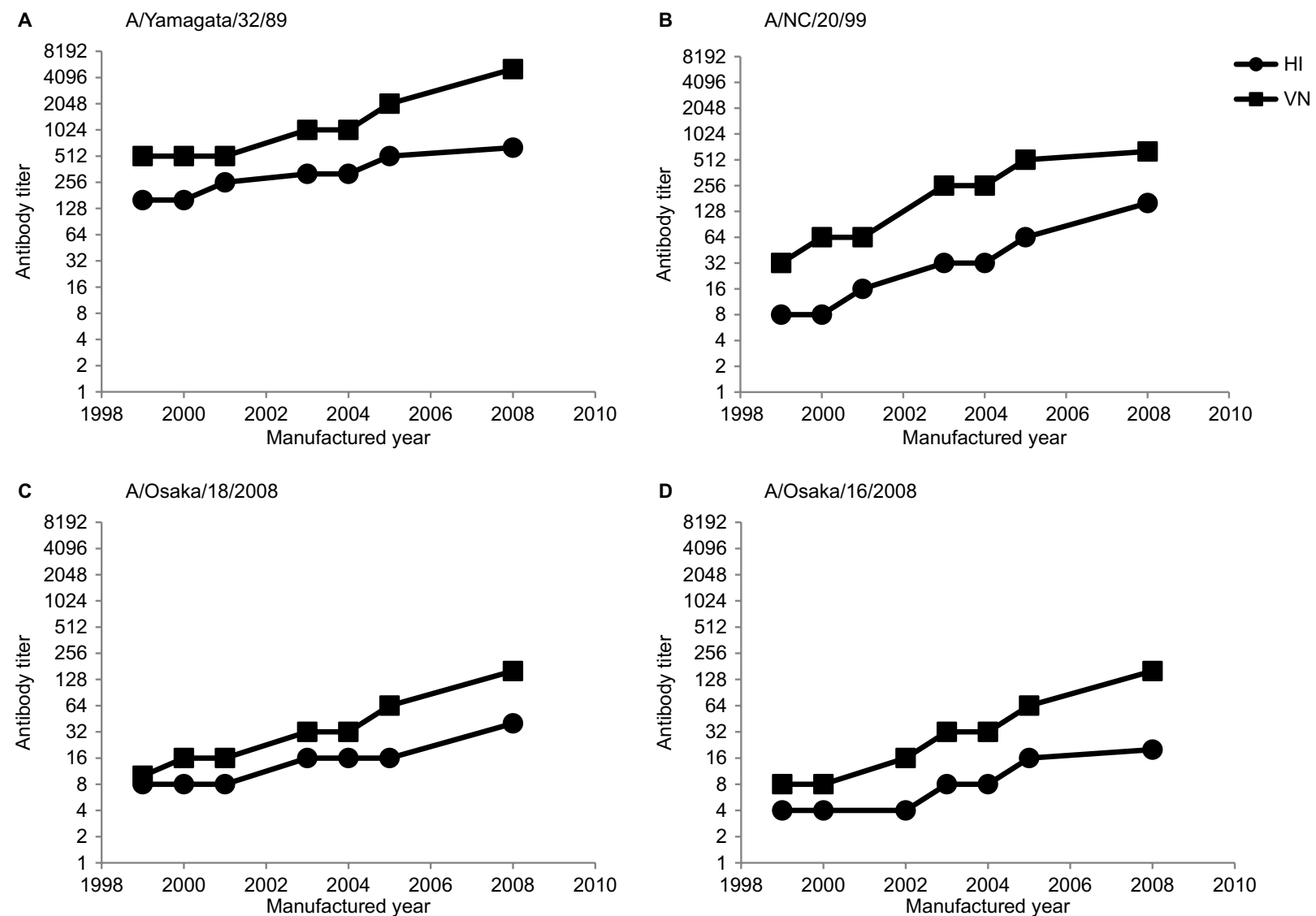

Figure 4 Changes in $\mathrm{HI}$ and VN titers against HINI influenza viruses isolated from 1989 to 2008 in representative V-IH lots manufactured from 1999 to 2008. Notes: Antibody titers against vaccine strains ( $\mathbf{A}$ and $\mathbf{B})$. Antibody titers against clinical isolates (C and $\mathbf{D})$. Closed circle: $\mathrm{HI}$ titer; closed square: $\mathrm{VN}$ titer. Abbreviations: $\mathrm{HI}$, hemagglutination inhibition; VN, virus neutralizing; $\mathrm{V}-\mathrm{IH}$, Venoglobulin $\mathrm{IH}$. 


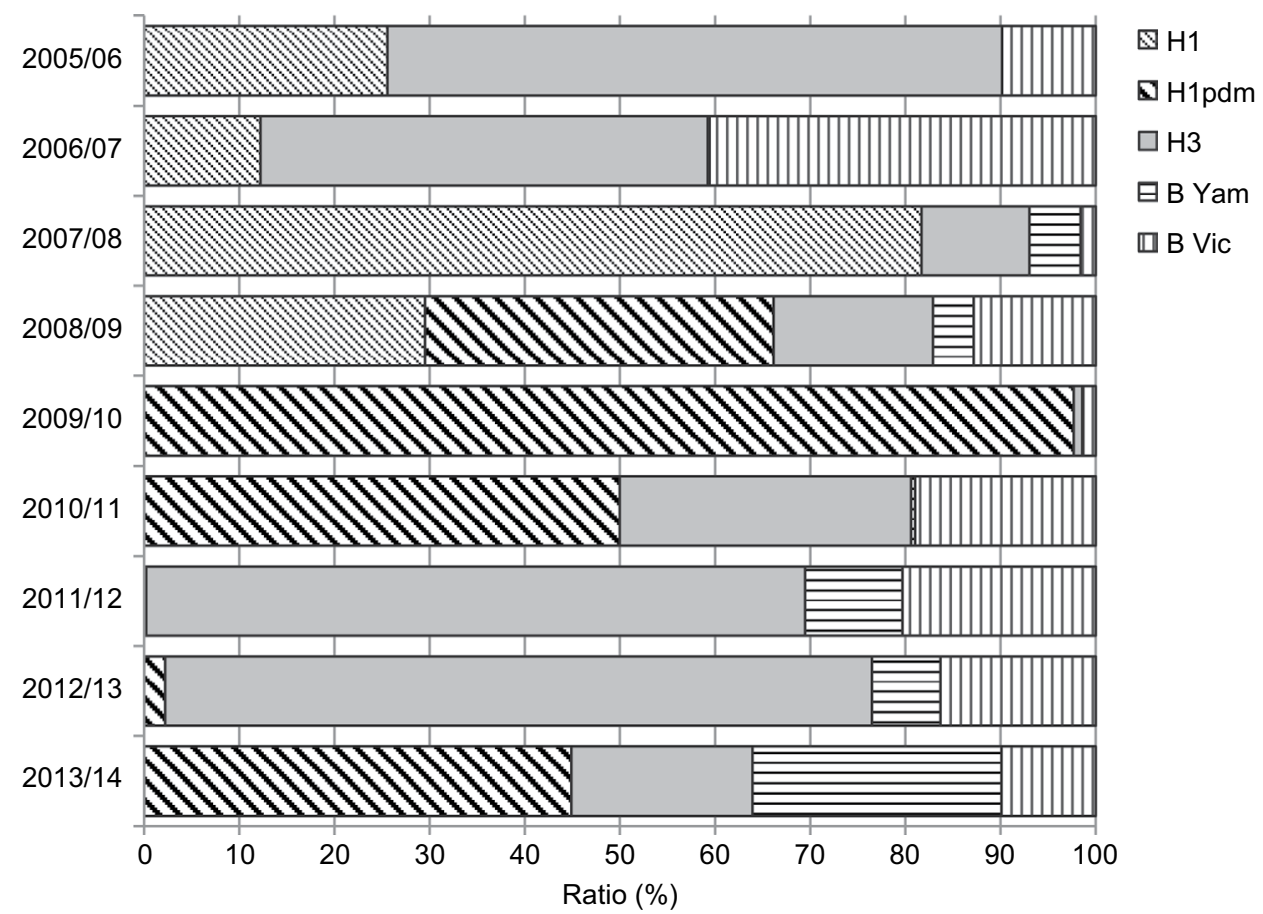

Figure 5 Influenza virus types isolated from 2005/2006 to 2014/2015 seasons in Japan.

Notes: Thin oblique line pattern: A/HINI (HI); thick oblique line pattern: A/HINI 2009 pandemic (HIpdm); gray: A/H3N2 (H3); horizontal line pattern: B/Yamagata-lineage (B Yam); vertical line pattern: B/Victoria-lineage (B Vic).

not undergo a major antigen change. The $\mathrm{HI}$ and $\mathrm{VN}$ titers were again correlated.

The $\mathrm{HI}$ and VN titers against the influenza $\mathrm{B}$ vaccine strains from seasons 2008/09 to 2014/2015 (B/Flo [2008/09], B/Bri [2009/10-2011/12], B/Wis [2012/13], and B/Mas [2013/14-2014/15]) are shown in Figure 3. Interestingly, the VN titers against B/Bri measured by Facilities A and B showed differing results. In contrast, the $\mathrm{VN}$ titers against $\mathrm{B} / \mathrm{Bri}$ (Victoria-group) and B/Wis (Yamagata-group) were similar. These results indicate that the titers were stable over long time periods. Note that the titers may indicate different results measured by different facilities.

These results indicate that, although the virus antigen underwent a change, the status of the donor population was not significantly altered. Taken together, this suggests that $\mathrm{HI}$ and VN titers can exhibit several patterns (stable, slowly increasing, and quickly increasing) when the target virus is changed; a significant antigenic shift has a greater impact than no major antigenic shift. The $\mathrm{HI}$ and $\mathrm{VN}$ titers are closely associated, though their mechanisms are different.

Variations in the $\mathrm{HI}$ and $\mathrm{VN}$ titers against $\mathrm{A} / \mathrm{H} 1 \mathrm{~N} 1$ influenza viruses isolated from 1989 to 2008 in representative IVIG lots manufactured from 1999 to 2008 were also evaluated. The $\mathrm{HI}$ and $\mathrm{VN}$ titers against the viruses increased slowly with increasing year of manufacture (Figure 4A-D). In addition, the IVIG lots exhibited higher $\mathrm{HI}$ and VN titers against older than recent isolates. The types of influenza viruses isolated from 2005/06 to 2014/15 are summarized from infectious agent surveillance reports (Figure 5). ${ }^{6}$ The proportion of isolated virus types varied in each season. Hence, the increase in $\mathrm{HI}$ and VN titers over extended time periods seems to be independent of the antigenicity of the epidemic viruses.

V-IH and Poly-N are manufactured using different process conditions. Thus, differences in the $\mathrm{HI}$ and VN titers of the three IVIG products were evaluated. The mean HI and VN titers are summarized in Table 2. The results indicate almost the same titer between V-IH and Poly-N ( $5 \%$ immunoglobulin $\mathrm{G}[\mathrm{IgG}]$ for both). In addition, the results with Poly-N 5 and $10 \%$ indicated that the titers were proportional to concentration. The dilution methods of these tests were $2 \times$ serial dilutions. Therefore, values within $2 \times$ of the titers are nonsignificant differences. These results suggest that the titers are not affected by the manufacturing process conditions, although they may be affected by virus strains.

\section{Discussion}

In this study, the HI and VN titers of IVIG against influenza $\mathrm{A} / \mathrm{H} 1 \mathrm{~N} 1, \mathrm{~A} / \mathrm{H} 3 \mathrm{~N} 2$, and $\mathrm{B}$ vaccine strains were evaluated. IVIG contains various antibodies against numerous human pathogens. Importantly, the individual donor plasma used for 
Table 2 Antibody titers of IVIG products

\begin{tabular}{|c|c|c|c|c|c|c|c|}
\hline \multirow[t]{2}{*}{ Seasons } & \multirow[t]{2}{*}{ Virus strain } & \multicolumn{3}{|l|}{ HI titers } & \multicolumn{3}{|l|}{ VN titers } \\
\hline & & $\begin{array}{l}\text { V-IH } \\
\text { (IgG: 5\%) }\end{array}$ & $\begin{array}{l}\text { Poly-N } \\
\text { (IgG: 5\%) }\end{array}$ & $\begin{array}{l}\text { Poly-N } \\
\text { (IgG: 10\%) }\end{array}$ & $\begin{array}{l}\text { V-IH } \\
\text { (IgG: 5\%) }\end{array}$ & $\begin{array}{l}\text { Poly-N } \\
\text { (IgG: 5\%) }\end{array}$ & $\begin{array}{l}\text { Poly-N } \\
\text { (IgG: 10\%) }\end{array}$ \\
\hline & A HINI & & & & & & \\
\hline \multirow[t]{2}{*}{$2012 / 13$} & A/California/7/2009 & $147 \pm 100$ & NE & NE & $450 \pm 402$ & NE & $\mathrm{NE}$ \\
\hline & & $(n=27)$ & & & $(n=27)$ & & \\
\hline \multirow[t]{2}{*}{$2013 / 14$} & A/California/7/2009 & $255 \pm 81$ & $224 \pm 105$ & $432 \pm 227$ & $1135 \pm 275$ & $864 \pm 454$ & $3136 \pm 2100$ \\
\hline & & $(n=22)$ & $(n=10)$ & $(n=10)$ & $(n=22)$ & $(n=10)$ & $(n=10)$ \\
\hline \multirow[t]{3}{*}{$2014 / 15$} & A/California/7/2009 & $320 \pm 0$ & $267 \pm 80$ & $512 \pm 175$ & $1482 \pm 480$ & $1138 \pm 282$ & $2048 \pm 701$ \\
\hline & & $(n=19)$ & $(n=9)$ & $(n=5)$ & $(n=19)$ & $(n=9)$ & $(n=5)$ \\
\hline & $\mathrm{A} \mathrm{H} 3 \mathrm{~N} 2$ & & & & & & \\
\hline \multirow[t]{2}{*}{$2012 / 13$} & A/Victoria/36I/20II & $|78 \pm 5|$ & NE & NE & $1256 \pm 123$ & NE & NE \\
\hline & & $(n=27)$ & & & $(\mathrm{n}=27)$ & & \\
\hline \multirow[t]{2}{*}{$2013 / 14$} & $\mathrm{~A} / \mathrm{Texas} / 50 / 2012$ & $178 \pm 60$ & $144 \pm 34$ & $240 \pm 84$ & $157 \mid \pm 549$ & $1664 \pm 810$ & $3456 \pm 1484$ \\
\hline & & $(n=22)$ & $(n=10)$ & $(n=10)$ & $(n=22)$ & $(n=10)$ & $(n=10)$ \\
\hline \multirow[t]{3}{*}{$2014 / 15$} & A/New York/39/20I2 & $152 \pm 25$ & $116 \pm 42$ & $224 \pm 88$ & $2425 \pm 842$ & $1489 \pm 675$ & $3584 \pm 1402$ \\
\hline & & $(n=19)$ & $(n=9)$ & $(n=5)$ & $(n=19)$ & $(n=9)$ & $(n=5)$ \\
\hline & B & & & & & & \\
\hline \multirow[t]{2}{*}{$2012 / 13$} & $\mathrm{~B} /$ Wisconsin/0I/2010 & $314 \pm 175$ & NE & NE & $1280 \pm 0$ & NE & NE \\
\hline & & $(n=27)$ & & & $(n=27)$ & & \\
\hline \multirow[t]{2}{*}{$2013 / 14$} & $\mathrm{~B} /$ Massachusetts/02/20I2 & $465 \pm 163$ & $480 \pm 169$ & $640 \pm 0$ & $2095 \pm 630$ & $2048 \pm 661$ & $4352 \pm 1237$ \\
\hline & & $(n=22)$ & $(n=10)$ & $(n=10)$ & $(n=22)$ & $(n=10)$ & $(n=10)$ \\
\hline \multirow[t]{2}{*}{$2014 / 15$} & $\mathrm{~B} /$ Massachusetts/02/20I2 & $589 \pm 120$ & $640 \pm 0$ & $896 \pm 351$ & $2088 \pm 634$ & $1422 \pm 427$ & $4608 \pm 1145$ \\
\hline & & $(n=19)$ & $(n=9)$ & $(n=5)$ & $(n=19)$ & $(n=9)$ & $(n=5)$ \\
\hline
\end{tabular}

Notes: Data are expressed as mean $\pm \mathrm{SD}$. V-IH and Poly- $\mathrm{N}$ are manufactured by different processes. Also, Poly- $\mathrm{N}$ comes in two different lgG concentrations: $5 \%$ ( $50 \mathrm{mg} / \mathrm{mL})$ and $10 \%(100 \mathrm{mg} / \mathrm{mL})$.

Abbreviations: IVIG, intravenous immunoglobulin; HI, hemagglutination inhibition; VN, virus neutralizing; V-IH, Venoglobulin IH; IgG, immunoglobulin G; Poly- N, Nisseki Polyglobin-N; NE, not examined; SD, standard deviation.

the IVIG lots manufactured from 2009 to 2014 examined in this study was collected several years prior to manufacture. Therefore, the $\mathrm{HI}$ and $\mathrm{VN}$ titers against vaccine strains exhibit time-lag effects, and the time-lag periods are not constant. With the lots used in this study, the lead time of V-IH was $>3$ years. Thus, the HI and VN titers of IVIG lots reflect the status of the donor population during the donation period.

Previously, we examined the $\mathrm{HI}$ and $\mathrm{VN}$ activities of IVIG lots against A/H1N1 2009 pandemic and A/H2N2 1957 pandemic. ${ }^{2,4}$ Interestingly, the results showed that IVIG possessed HI and VN activities against these viruses, although most donors were not exposed to either pandemic. These results suggest that the donor population plasma maintained cross-reactive globulins against the pandemic A/H1N1 and A/H2N2 viruses. Prior to this study, the HI and VN titers against seasonal influenza viruses over extended time periods had not been examined. Importantly, variations in the HI and VN titers before and after a major antigenic change, such as a pandemic caused by a novel virus, had not been evaluated.

The results of this study showed that all IVIG lots contained $\mathrm{HI}$ and $\mathrm{VN}$ activities against seasonal influenza vaccine strains. Overall, $\mathrm{HI}$ and VN activities were stable over short time periods and slowly increased over extended periods, with little variance following changes in the vaccine strain. In contrast, in specific cases such as the major antigenic change that occurred during the 2009 pandemic, the HI and $\mathrm{VN}$ activities decreased, but subsequently increased following the spread of the virus to the donor population. These results suggest that IVIG contains stable levels of specific and cross-reactive antibodies against seasonal influenza viruses. In addition, the $\mathrm{HI}$ and $\mathrm{VN}$ titers varied slowly over extended periods, except when the vaccine strain was altered or a major antigenic change occurred in a pandemic.

Variances in HI and VN titers against influenza viruses isolated from 1989 to 2009 in representative IVIG lots manufactured from 1999 to 2008 indicate that these titers increased with year of manufacture. This result suggests that the level of HI and VN activity of IVIG reflects the effects of vaccination programs and natural infection of donor populations. Furthermore, monitoring $\mathrm{HI}$ and VN titers over extended time periods is important, especially when the vaccine strain is changed or an antigenic shift occurs, such as in the 2009 pandemic. Further studies are required to elucidate the mechanism(s) underlying the maintenance of antibody titers against influenza viruses over extended time periods and how they are affected by antigenic shift and drift. 
IVIGs contain neutralizing antibodies against various influenza viruses and are thus expected to have a therapeutic effect. Unfortunately, knowledge of the therapeutic effect and the mechanism of IVIG against influenza has been limited, although some findings have been reported. ${ }^{7-10}$ Evaluation of the therapeutic effect of IVIG against influenza using an animal model has also been reported. ${ }^{11,12}$ IVIGs derived from plasma collected prior to 2009 showed a therapeutic effect on mouseadapted $\mathrm{A} / \mathrm{NC}$; however, the effect against the 2009 pandemic virus was lower than against $\mathrm{A} / \mathrm{NC} .{ }^{11}$ IVIG containing a high titer of antibodies against the 2009 pandemic virus elicited $100 \%$ survival in contrast with the $50 \%$ survival using IVIGs derived from plasma collected prior to $2009 .{ }^{12}$ The mechanism underlying this effect requires further study because the efficacy of IVIG against influenza has yet to be verified.

\section{Conclusion}

IVIG exhibited significant $\mathrm{HI}$ and $\mathrm{VN}$ titers against all influenza strains investigated in this study. The $\mathrm{HI}$ and VN titers against seasonal influenza vaccine strains, including past strains, were stable over short time periods and increased slowly over extended periods. Our results suggest that the donor population maintains both specific and cross-reactive antibodies against seasonal influenza viruses over extended periods, except in cases of pandemic viruses with a major antigen change. Moreover, our results suggest that new antibodies were acquired and added to globulin, including a few cross-reactive antibodies, when antigenic shift occurred. New antibodies were also acquired against mutated viruses and added to globulin, maintaining reactivity to past viruses when antigenic drift occurred. Monitoring of VN titers following major antigenic changes, such as an antigenic shift, will be valuable for evaluating the function of IVIG against pandemic influenza strains.

\section{Acknowledgments}

This study was conducted in part as a collaborative research project between Osaka University, Rakuno Gakuen University, The Research Foundation for Microbial Diseases of Osaka University, and the Japan Blood Products Organization (formerly the Benesis Corporation). The authors thank Dr. Kaoru Sakai (Japan Blood Products Organization) for valuable discussions and technical support. We would also like to thank Editage (www.editage.jp) for English language editing.

\section{Disclosure}

H. Onodera, T. Urayama, and M. Yunoki are employees of the Japan Blood Products Organization. T. Urayama and M. Yunoki are also former employees of the Benesis Corporation. H. Onodera is a former employee of the Japanese Red Cross Society. K. Maeda, R. Kubota-Koketsu, K. Hirota, Y. Okuno, and K. Ikuta are employees of The Research Foundation for Microbial Diseases of Osaka University. K. Ikuta was also a Professor at Osaka University. $\mathrm{K}$. Takahashi is currently affiliated to the Department of Clinical Laboratory, International University of Health and Welfare Hospital. The authors report no other conflicts of interest.

\section{References}

1. Pichyangkul S, Jongkaewwattana A, Thitithanyanont A, et al. Crossreactive antibodies against avian influenza virus A (H5N1). Emerg Infect Dis. 2009;15(9):1537-1539.

2. Yunoki M, Kubota-Koketsu R, Urayama T, et al. Significant neutralizing activity of human immunoglobulin preparations against pandemic 2009 H1N1. Br J Haematol. 2009;148(6):948-963.

3. Hong DK, Tremoulet AH, Burns JC, Lewis DB. Cross-reactive neutralizing antibody against pandemic $2009 \mathrm{H} 1 \mathrm{~N} 1$ influenza A virus in intravenous immunoglobulin preparations. Pediatr Infect Dis J. 2011; 30(1):67-69.

4. Kubota-Koketsu R, Yunoki M, Okuno Y, Ikuta K. Significant neutralizing activities against $\mathrm{H} 2 \mathrm{~N} 2$ influenza $\mathrm{A}$ viruses in human intravenous immunoglobulin lots manufactured from 1993 to 2010. Biologics. 2012;6:245-247.

5. Okuno Y, Tanaka K, Baba K, Maeda A, Kunita N, Ueda S. Rapid focus reduction neutralization test of influenza $\mathrm{A}$ and $\mathrm{B}$ viruses in microtiter system. J Clin Microbiol. 1990;28:1308-1313.

6. NIID [webpage on the Internet]. Infectious Agents Surveillance Report. Available from: http://www.nih.go.jp/niid/ja/typhi-m/iasrreference/230-iasr-data/5492-iasr-table-v-p.html. Accessed December $14,2016$.

7. Gokturk B, Pekcan S, Guner SN, et al. Efficacy of intravenous immunoglobulin treatment in immunocompromised children with $\mathrm{H} 1 \mathrm{~N} 1$ influenza: a clinical observation. Clin Respir J. 2016;10(2):223-230.

8. Davey RT Jr, Markowitz N, Beigel J, et al. INSIGHT FLU005: an AntiInfluenza Virus Hyperimmune Intravenous Immunoglobulin Pilot Study. J Infect Dis. 2016;213(4):574-578.

9. Donovan S, Bearman GM. Use of intravenous immunoglobulin in critically ill patients. Curr Infect Dis Rep. 2014;16(12):447.

10. Hung IF, To KK, Lee CK, et al. Hyperimmune IV immunoglobulin treatment: a multicenter double-blind randomized controlled trial for patients with severe 2009 influenza A(H1N1) infection. Chest. 2013;144(2): 464-473.

11. Hagiwara K, Kawami S, Kato-Mori Y, et al. Protective role of human intravenous immunoglobulin from influenza A virus infection in mice. Open Hematol J. 2012;6:8-11.

12. Hohenadl C, Wodal W, Kerschbaum A, et al. Hyperimmune intravenous immunoglobulin containing high titers of pandemic H1N1 hemagglutinin and neuraminidase antibodies provides dose-dependent protection against lethal virus challenge in SCID mice. Virol J. 2014;11:70. 


\section{Publish your work in this journal}

Biologics: Targets and Therapy is an international, peer-reviewed journal focusing on the patho-physiological rationale for and clinical application of Biologic agents in the management of autoimmune diseases, cancers or other pathologies where a molecular target can be identified. This journal is indexed on PubMed Central, EMBase, and Scopus.
The manuscript management system is completely online and includes a very quick and fair peer-review system, which is all easy to use. Visit http://www.dovepress.com/testimonials.php to read real quotes from published authors.

Submit your manuscript here: https://www.dovepress.com/biologics-targets-and-therapy-journal 